\title{
A Brief Analysis on the Application of Internet in Physical Education and Countermeasures \\ Yaoliang Zhang
}

Zhuhai College of Jilin University, Guangdong Zhuhai 519041

\begin{abstract}
Nowadays, with the development of society, the Internet has gradually occupied an important position in the social composition and more or less affects different areas of life including physical education. The real education reform must conform to the development of the Internet Era. On the current education situation, the introduction of the network communication tools, different automation software and computer assisted instruction have greatly improved the actual response in the class. However, there are still many problems. Only by paying more attention to the application of the Internet technology and innovating the teaching mode based on the Internet, can we get a real development in the physical education.
\end{abstract}

Keywords: Physical education; The internet; CAI; Innovation; Interaction

\section{浅谈互联网在体育教育中的应用现状及改进对策}

\author{
张尧良 \\ (吉林大学珠海学院, 广东珠海 519041)
}

摘要: 现如今随着社会的发展, 互联网逐渐占据了社会组成中的重要地位, 对生活中包括体育教育在内的各个不同领域 都产生了或多或少的影响。真正意义上的教育改革必须要顺应互联网时代的发展。就现在的教育现状来看, 已经实现了网络 交流工具、各种自动化软件和计算机辅助教学的引入，使得课堂教学的实际反响有了很大程度的改善，但存在的不足依然很 多。只有对互联网技术的运用进一步重视、不断创新互联网教学模式, 体育教育才能得到真正的发展。

关键词：体育教育；互联网；CAI；创新；互动

\section{引言}

在信息全球化时代下，互联网技术不断改变着信息传播的方式，一场具有深远影响和重大意义的改革 正如火如茶地展开着。整个教育领域不可避免地受到了新技术带来的冲击, 从不同层面上打破了传统教育 模式, 丰富了学生的学习过程。作为高校的必要课程之一, 体育课程的教育模式也受到了互联网技术的冲 击。因此, 有效整合体育教学和互联网技术成为了新的研究热点, 同时也是促进体育教育发展的重要途径。

\section{1 体育教育中互联网技术的运用现状}

以计算机技术为基础建立的互联网技术具有的优势在于其协作性、共享性以及灵活性和开放性，有利 于丰富教学手段和教学资源, 与此同时, 还能从一定程度上对学生的视野起到拓宽作用。相比于原始的文 理知识课堂教学 ${ }^{[1]}$, 体育教学对学生的实践性和参与性有更高的要求, 更加注重教学过程中良好氛围的营 造, 这更凸显了互联网技术的使用在体育教育中的重大意义。现如今体育教育中已有的互联网技术运用形 式如下:

\section{1 CAI}

CAI, 即计算机辅助教学 ${ }^{[2]}$, 指的是各种以计算机辅助为前提的教学活动, 其运用范围包括开展教学训 练、对教学进程进行妥善安排以及与学生进行教学内容上的讨论等。CAI 能够通过声音、图像和视频等的 使用使得教学内容更加丰富多彩, 学生对学习内容的接受程度得到了有效提升。传统模式的教学无论是在 
内容上、手段上还是形式上都太过单调, 而 CAI 对知识库、网络通信和多媒体等的应用成功克服了这些缺 点, 使得学习质量有所提升的同时, 学习时间也得到了有效控制, 是一场对教育模式的全面革新。

教师备课继而对学生进行知识的灌输是体育教育的传统模式, 学生在整个学系中始终处于一种被动接 受的状态, 机械地在教师指导下对学习内容进行反复演练。然而, 通过人机互动, CAI 能够对学生的接受 能力和程度进行及时反馈, 并在此过程中作出教学重点的转移和相关薄弱教学内容的强化, 这种双向交流 使得教学过程更加具有灵活性, 学生的学习动力和兴趣也能得到有效地调动 ${ }^{[3]}$ 。CAI 可以利用强大的视音 媒介功能, 用一种更加形象生动的方式将相关体育知识传播给学生, 无论是精细的体育动作还是繁杂的运 动力学原理都能得到完美展示。与此同时, 许多复杂动作的规范性也能在计算机辅助技术的指导之下得到 保障, 有利于学生对规范动作的学习。除此之外, 在对体育的基本动作有所研究之后, 计算机技术还能对 新动作进行设计，使其朝着更高难度的方向发展，对于高水准体育人才的培养具有不可或缺的价值。

\section{2 自动化软件}

在体育教学的日常工作中, 许多能够有效提高办公效率的软件受到了广泛的运用, 如 Exce1 和Word 等, 已经成为了体育教师统计数据和编写教案的重要手段 ${ }^{[4]}$ 。除此之外, 为了满足体育专科教学的特殊要求, 一系列更具有针对性的软件也成了开发商研究的焦点。如 “体质监测系统” 等软件, 就是在实际体育教学 的基础之上研发出来的，和体育教学的特殊性相符，使得体育教学的效率得到了有效地提升。

一些学校为了体育考核能够更加便利, 利用计算机创建了体育测试的专用试题库，能够对试题随机调 取, 并在学生答题之后自动评判对错, 给出最后的得分, 既能够对考核标准有所规范, 也使得体育老师的 工作效率有所提高。

计算机技术提高了体育老师工作效率的同时，还能使其省下更多的时间用在体育领域的研究之上。在 计算机技术的指导之下, 体育教师可以对前沿文献中的知识进行有效提取, 及时获得新兴数据, 并在和其 他优秀体育教育人才的交流之中有所进步, 使得体育教学内容有所丰富的同时, 科研水平还有显著性的提 升。

\section{3 网络互动交流}

现如今, 体育教学网站的建立成为了高效体育教学的重要途径, 学生和老师能够在此平台上进行亲密 的交流, 体育课程的形式更加多彩, 学生体育学习的自主性也有所提高, 学生与学生、学生与老师之间的 合作交流更加密集, 学习效率自然不断提高。除此之外, 网站上还设有其他院校体育教学的网站链接, 体 育教育信息的来源方式更多, 学生能获取的信息内容也就更加充实。

与此同时, 微信和 $\mathrm{QQ}$ 等网络聊天软件正逐步成为学老师辅导学生学习的重要交流工具, 既能满足体 育教学的个体差异性, 也能缩短老师和学生在课堂上形成的无形距离, 学生也能心无芥蒂地全身心投入到 体育学习之中。

\section{2 体育教育中互联网技术运用存在的问题}

\section{1 学校重视程度不足}

尽管信息全球化时代之下，人们对于互联网技术运用的认可度有了一定程度的提升，然而学校对于体 育教学的重视程度不够, 对于将互联网技术运用到体育教学之中更加忽视, 直接导致了体育经费的不足。 由于经费上的严重限制, 互联网技术运用所需的软件和硬件就不能得到有效开发。此外, 由于互联网技术 
重视程度的不足, 其运用培训的课程开设更加稀少, 导致体育教师对互联网联合教学的认识不充分, 不能 将互联网技术有效运用在日常的体育教学中。因此, 对于互联网辅助教学来说, 学校的重视具有相当的关 键性, 只有保障人力、物力方面的投入, 互联网教学才能切实地开展起来。教师的教学积极性才能得到有 效调动。

\section{2 计算机辅助教学形式化}

就目前计算机技术在日常教学中的使用情况来看, 学校真正在乎的是对于教学新形式的使用, 多媒体 设备的安装和计算机课件教学等都是为了显得与时俱进、显得与互联网时代不相矛盾。看起来已经普及了 体育教学中的计算机辅助教学方式、改革了传统教育模式, 然而也只是将板书改成了电子形式, 将枯燥的 口头讲解转变为更为生动的图音播放, 从根本上来说, 呆板的填鸭式教育并未有所改变 ${ }^{[5]}$ 。形式上的教学 转变是没有任何意义的, 更加严重的是, 电子课件很少更新, 老师在上课时对课件僵硬的念白甚至对其本 身即兴发挥的创造力起到了一定程度的约束作用，一成不变的教学内容只会让学生逐渐失去对体育课堂的 兴趣。

\section{3 互动性不足}

就 CAI 来说, 学生和老师之间的角色转换是整个学习过程最主要的目的, 老师不再是单纯的知识传播 者, 学生也不局限于知识的受承者, 由被动学习转变为主动获取, 这不仅仅是一个对学生探索精神和独立 思考能力的培养过程 ${ }^{[6]}$, 也是使其创造性和主动性不断提高的过程。现如今, 互联网技术在体育教育中的 使用愈加广泛, 然而学生将知识强行灌输给学生的传统观念没有改变。尽管学校建立了体育教学的专用网 站, 然而却没有对学生和老师之间的交流互动进行充分考虑, 其关注的重点仍然在于如何传播知识, 因此 教学互动版块并没有设立。在体育内容方面, 甚至没有做到体育课堂内容和网站课程的良好衔接, 学生根 本无法从中获取有利于课堂学习的知识, 网站成为了鸡肋。此外还有网站维护方面的一系列问题, 都导致 了网站建设成为了面子工程, 对学生体育学习没有起到实质性的促进作用。

\section{3 改进措施}

\section{1 加强学校互联网硬件和软件建设}

首先，有关互联网教学的基础设施投入非常重要，网络服务的软件设施方面也不能忽略。重视对互联 网专业人才的培养, 在体育专业软件的开放上投入更多资金。与此同时, 图书馆网络信息服务建设也要有 一定程度的加强, 及时对体育资源数据库进行更新, 使得学生能够便利地阅读最新体育文献, 获取最新的 专业信息。

\section{2 提高教师互联网应用水平}

在全球信息化时代之下, 体育教育和互联网技术的结合成为了大势所趋。然而, 在 CAI 推广过程之中, 广大体育教师的传统教学理念仍然存在着不容忽视的束缚作用因此, 积极转变体育教师的传统思想成为了 教学模式改革的第一步。在此过程中, 兴趣的培养起到了积极的推动作用。与此同时, 学校也要重视教师 运用 CAI 能力的培养，适当开展一些技术培训活动，建设好互联网技术方面的人才队伍。

\section{3 增强计算机辅助教学课件的创新性}

在体育教学的过程之中, 针对学生群体的差异性, CAI 课件也不应该千篇一律, 毫无个性。很多时候, 完整课件的讲述完全没有必要, 课堂的重点放在学生需要或者感兴趣的内容上, 在解释一个简单的体育原 
理时, 也只需要播放有高度相关性的一小段视频即可。这些都强调了体育教学中的特殊性和针对性。因此, 能够根据教学需求的改变对教学信息资源进行组合运用的积件受到了推广 [7]。其丰富的素材和多变的组 合使得教师拥有了广泛的选择范围, 教师在利用计算机辅助教学的同时, 还能维持其原有的创造性以充实 课堂内容。积件的运用优势体现在以下四点:

(1) 积件保障了教师设计教学课件的权力, 对人的主体性十分重视, 学习的主动权掌握在老师和学 生的手中 [8]。师生才是教学过程中的主体, 教学课件不会成为体育教学的束缚, 而是以其灵活性和创造 性对课件教学起到了有利的推动作用。

（2）教材版本和课程体系的改变和积件之间没有本质关联，无论在何种情况下，积件都能通过创造 性的组合适应教学活动的改变。

（3）积件组合形式的多样性决定了其具有良好的可操作性和实用性。

(4) 积件存在的目的不是为了改造师生原本的体育理念, 只是作为教学的辅助工具提供了师生学习 的平台。

因此, 要想提升对计算机辅助教学的认识层面, 实现课件思想到积件思想的转变是重要的理论前提。

\section{4 改革网络教学模式}

实时在线方式是在互联网技术的基础之上，对于传统课堂的模仿，远程沟通是其主要优势所在 [9]。 师生之间能够进行有效互动, 有利于资源的共享。即使不共处一地, 老师也能在学生学习过程中起到约束 和督促作用。此外, 离线或非实时方式也是网络教学的重要方式之一, 学生能够在线获取信息和资源, 自 主安排学习。其优势在于学习过程的自主性较高, 资源的使用也可重复进行。学生可向老师反馈出学习中 的难点, 老师可安排固定时间统一解惑，学生群体之间也可通过网络交流工具展开自主讨论。

2013 年微信就已宣布, 其用户总人数达到了 3 亿, 其主要使用群体一般为各级学生[10]。由此我们联 想到, 体育教学可以与微信相结合, 实现网络虚拟教室的构建。具体教学过程中, 老师可以先建立一个班 级的微信群, 在群里发布教学内容, 学生也可在群里提出学习中遇到的难点, 老师和其他学生都可以作出 解答, 相对应的, 老师也可发布专题让学生们积极讨论, 共同查找资料寻找解决方法, 或者通过分工合作 的方式各自研究自己分配到的学习内容。

\section{4 总结}

综上所述, 互联网技术在体育教育领域已经有了一定的研究成果, 在教育管理和课程教学方面也有重 要的研究和发展意义。然而, 其存在的一些劣势层面也决定了我们要在现有的互联网技术运用基础上作出 改进, 体育教学的互联网改革成为了大势所趋。加强学校对互联网和体育教学结合程度的同时, 也要注重 教师专业素质的提升和计算机辅助教学课件水平的提高, 勇于创新, 翻开网络教学的新篇章, 真正意义上 实现体育教学模式本质性的改革。

\section{参考文献:}

[1] 王晶. 浅谈互联网对高校体育教育的影响及对策 $[J]$ ．才智，2013 (14).

[2] 王昕, 刘皓月, 李洋. 将 “互联网+” 应用在高校体育教学管理中的研究 [J]. 中小企业管理与科技 (下旬刊), 2016 (03).

[3] 姜勇, 王东海. 移动互联网对高校体育教学影响的研究 [J]. 南京体育学院学报 (自然科学版), 2015 (05).

[4] 温小强. “互联网”对高校思想政治教育工作的影响及对策 $[J]$. 甘肃联合大学学报 (社会科学版), 2009 (03). 
[5] 李航. 高校体育多媒体教学应用的现状分析 $[J]$ 。 内江科技，2009 (08).

[6] 倪隽. 多媒体在高校体育教学中的实践性探索 $[J]$. 教育与职业，2009 (14).

[7] 李美凤. 技术视野下的教师发展论 [M]. 北京: 教育科学出版社, 2011:73.

[8] 黄建军, 郭绍青. WebX. 0 时代的媒体变化与非正式学习环境创建 $[J]$. 中国电化教育, 2010 (4).

[9] 李明鉴. 谈互联网在学校体育教学中的应用 $[J]$. 创新教育, 才智, 2015 (225).

[10］王俊鹏. 计算机与多媒体在体育教学中的运用 [J]. 当代体育科技, $2012(10)$.

\section{References:}

[1] Wang Jing. On Influence and Countermeasures of Internet on College Physical Education [J].Caizhi, 2013(14)

[2] Wang Xin, Liu Haoyue, Li Yang. Research on Applying "Internet +" in Universities Sports Teaching Management [J].Management and Technolosy of SME (the Last Ten-Day Period of a Month), 2016(03).

[3] Jiang Yong, Wang Donghai. Research on Effect of Mobile Internet to Physical Education Teaching in Colleges and Universities [J].Journal of Nanjing Institute of Physical Education(Natural Science),2015(05).

[4] Wen Xiaoqiang. Influence and Its Countermeasures of "Internet" to Ideological and Political Education Work in Colleges and Universities [J].Journal of LanZhou University of Arts And Science (Social Sciences Edition),2009(03).

[5] Li Hang. Present Status Analysis of Application of Multimedia Teaching in Colleges and Universities [J].Nei Jiang Science and Technology, 2009 (08).

[6] Ni Jun. Practical Exploration of Multimedia in Sports Teaching in Colleges and Universities [J].Education and Vocation, 2009 (14).

[7] Lei Meifeng. Teacher Development Theory in the Perspective of Technology [M].Beijing: Educational Science Publishing House, 2011: 73.

[8] Huang Jianjun, Guo Shaoqing. Media Changes in WebX.0 Age and creation of Informal Learning Environments [J].China Educational Technology, 2010 (4).

[9] Li Mingjian. On application of Internet in School Physical Education [J].Innovative Education and Intelligence, 2015 (225).

[10] Wang Junpeng. Application of Computers Computers Multimedia in the Teaching of Physical Education [J].Contemporary Sports Technology, 2012 (10). 